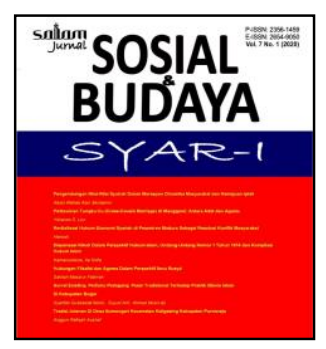

P-ISSN: 2356-1459. E-ISSN: 2654-9050

Vol. 8 No. 3 (2021), pp. $699-710$

DOI: 10.15408/sjsbs.v8i3.20577

http://journal.uinjkt.ac.id/index.php/salam/index

\title{
Demokrasi dalam Keluarga di Ruang Komunikasi Digital Masa Kini*
}

\begin{abstract}
Ambros Leonangung Edu ${ }^{1}$ Richard A. Nelwan ${ }^{2}$
Universitas Katolik Indonesia Santu Paulus Ruteng, Nusa Tenggara Timur

d.

Abstract

$10.15408 /$ sjsbs.v8i3.20577

This paper background describes about democratic values such as equality, honesty, openness, freedom due to the intervention of digital technology. The basic assumption of this paper is that democracy which is known to the public is accepted and has strong roots in the family lives. Family is the first place a person gets to know democracy. Home is a space for the seeds of democracy to grow. Democracy in the family matures the democratic process in society and the state. A democraticperson in family is a democratic cittizen in state life. The purpose of this paper is to explore democratic values in the family as a place for the development of democracy at the state level, and how the shift in democracy at the family level occurs due to the presence of digital technology which distorts communication, relationships, and the value of equality. The description in this paper comes to the conclusion that there is a good side to democracy in a family that grows above physical and emotional relationships, direct and face-to-face relationships. The facts that occur in today's families, the breakdown, estrangement, and disharmony in today's families, one of which is triggered by the lack of direct communication due to excessive entry of digital technology.
\end{abstract}

Keywords: Democracy; Family; Communication; Digital Technology

\begin{abstract}
Abstrak
Tulisan ini bertolak dari kemunduran nilai-nilai demokrasi di dalam seperti kesetaraan, kejujuran, keterbukaan, kebebasan, akibat intervensi teknologi digital. Asumsi dasar tulisan ini adalah bahwa demokrasi yang dikenal publik pun diterima dan berakar kuat dalam keluarga. Keluarga adalah tempat pertama kali seorang mengenal demokrasi. Rumah adalah ruang bagi bertumbuhnya bibit-bibit demokrasi. Demokrasi dalam keluarga mematangkan proses demokrasi dalam masyarakat dan negara. Seorang yang demokratis dalam keluarga berarti demokratis dalam kehidupan negara. Tujuan penulisan ini adalah untuk mengeksplorasi nilai-nilai demokrasi dalam keluarga sebagai tempat bertumbuhkembangnya demokrasi di tingkat negara, dan bagaimana pergeseran demokrasi pada tataran keluarga terjadi akibat kehadiran teknologi digital yang mendistorsi komunikasi, relasi, dan nilai kesetaraan. Uraian dalam tulisan ini sampai pada kesimpulan bahwa terdapat sisi baik demokrasi dalam keluarga bertumbuh di atas hubungan fisik dan emosi, hubungan langsung dan tatap muka. Fakta yang terjadi pada keluarga-keluarga masa kini, keretakan, kerenggangan, dan disharmonisasi dalam keluarga-keluarga masa kini, salah satunya dipicu oleh kurangnya komunikasi langsung akibat masuknya teknologi digital yang berlebihan.
\end{abstract}

Kata Kunci: Demokrasi; Keluarga; Komunikasi; Teknologi Digital

* Received: May 23, 2021, Revision: May 26, 2021, Published: June 5, 2021.

${ }_{1}^{1}$ Ambros Leonangung Edu adalah dosen Universitas Katolik Indonesia Santu Paulus Ruteng, Email: ambros.leonangung@gmail.com

${ }^{2}$ Richard A. Nelwan adalah Alumnus Pascasarjana Teknologi Tropik Fachhochschule Köln, Jerman. Email: rich.a_nel@yahoo.com 


\section{A. PENDAHULUAN}

Kita memasuki babak kehidupan yang mencengangkan ketika angin teknologi digital berhembus kencang. Era yang sangat dinamis serentak mengantar kita pada problem sosial yang kian kompleks. Mekanisme serba digital mengubah secara radikal cara kita berpikir, bekerja dan bahkan bersosialisasi. Kita tidak harus berinteraksi secara tatap muka, melainkan dapat terhubung dalam jaringan relasi yang bersifat virtual. Konektivitas dilakukan melalui macam-macam gadget high technology dengan varian-variannya seperti smartphone, laptop, komputer, dan apple. ${ }^{3}$ Digitalisasi komunikasi seperti ini menciptakan realitas sosial yang baru bernama "masyarakat digital" (digital society). Masyarakat digital merupakan ekses dari proses dua arah: globalisasi dan individualisasi secara bersamaan. Individu ibarat sebuah sistem terbuka (global) yang berorientasi pada visi masa depan serentak menciptakan beragam komunikasi secara maksimal pada saat ini dan di sini juga. Setiap individu dapat mengimplementasikan beragam proyek dalam keterbatasan intelektualnya, yang tidak hanya karena kemudahan dari teknologi tetapi juga karena dinamisme sebagai unsur penting dalam realitas masyarakat digital masa kini. ${ }^{4}$

Digitalisasi segala sesuatu sangat menggiurkan baik bagi orang-orang yang menangani urusan negara, lembaga bisnis, politik, sekolah maupun komunitas paling privat - keluarga dan perkawinan. Kita menghadapi pola-pola karakter baru yang menimpa keluarga-keluarga, yang begitu gampang terlihat di mana-mana. Kehidupan keluarga yang ditunjang oleh teknologi itu tanda kemajuan tak ternilai, yang mendorong berbagai aktivitas dan proyek keluarga untuk diselesaikan secara cepat dan tuntas dalam sekejap. Pekerjaan selama masa pandemi Covid-19 tak ayal dapat dilakukan dari rumah. Kegiatan pendidikan anak dalam keluarga terbantu oleh aplikasi-aplikasi ramah anak.

Komunikasi gadget diadaptasi dari pola-pola komunikasi manusia, tetapi ketika ditransfer melalui aplikasi, komunikasinya telah tereduksi kepada sifat yang lebih transaksional dan faktis. Ia cenderung berciri ucapan-ucapan pendek atau singkat sekedar untuk menjaga relasi sosial. Kenyataan memperlihatkan bahwa, intensitas komunikasi dan relasi secara virtual dipicu oleh ragam tampilannya, misalnya game online dan offline, hiburan, berita, informasi gaya hidup, sehingga sebagian orang lebih asyik dengan konten-konten, durasi dan frekuensi tanpa batas yang mengganggu dialog dan interaksi dalam keluarga. Distorsi komunikasi interpersonal pun terjadi. Kecanduan gadget mendatangkan berbagai akibat seperti depresi, labil, gampang marah, penurunan neuron dan kognisi, ${ }^{5}$ gangguan mata pada anak, mengabaikan kehadiran orang sekitar, posesif, suka meniru-niru gaya iklan, over-expossure (suka eksis) di media sosial, penurunan prestasi belajar, rentan terhadap pornografi dan

${ }^{3}$ Inda Lestari, Agus Wahyudi Riana, Budi M. Taftarzani, “Pengaruh Gadget Pada Interaksi Sosial Dalam Keluarga", dalam Prosiding KS: Riset E PKM, Volume: 2 Nomor, hlm. 204.

${ }^{4}$ Ilya Elvin, "Cultural Trends in a Ditial Society", dalam Proceedings of TMCE 2014, May 19-23, 2014, Budapest, Hungary, hlm. 14.

${ }_{5}$ Marianus Mantovanny Tapung, Ambros Leonangung Edu, Petrus Redy Partus Jaya. (2019). "Kemampuan Bermedia dan Daya Kritis Para Mahasiswa Di Kabupaten Manggarai - Flores", dalam SALAM; Jurnal Sosial \& Budaya Syar-i FSH UIN Syarif Hidayatullah Jakarta Vol. 6 No. 2, hlm. 130. 
pornoaksi serta kejahatan dunia maya, ${ }^{6}$ yang merusak bibit-bibit persaudaraan dalam keluarga.

Teknologi digital adalah kawan akrab dengan sistem perekonomian global yang berorientasi profit. Maka, tidak heran, keakraban dengan gadget secara implisit akrab dengan sifat-sifat ekonomi yang dibawa serta, seperti materialisme, hedonisme, dan konsumerisme. Implikasinya, paradigma perkawinan dan relasi serta obsesi keluarga bergeser dari kebutuhan emosional, kasih sayang, pendidikan, dan religiositas kepada kepentingan ekonomis. Mobilitas menjadi fenomena utama ketika para anggota keluarga lebih sibuk mengisi pundi-pundi ekonomi keluarga. Tak jarang setiap anggota keluarga sulit bertemu satu sama lain, sementara anak-anak berada di bawah asuhan pediatrik atau pembantu rumah tangga. Jarang makan di rumah dan jarang bertemu anak atau orang tua, adalah gejala degradasi nilai-nilai demokrasi, yang pada gilirannya secara tak sadar mengubah keluarga dari keluarga (home) kepada rumah (house).

Kajian ini menggagaskan cela-cela yang perlu dilakukan untuk mengembalikan keluarga pada martabatnya sebagai komunitas demokratis, tempat di mana bertumbuh persaudaraan dan kebersamaan sejati, ruang kembangnya kemanusiaan dalam semangat demokratis. Demokrasi itu sendiri sebagai sebuah proses politik global namun benih-benihnya (seedbed) bertumbuh di dalam ruang perkawinan dan keluarga. Seturut pakar demokrasi tidak hanya demokrasi negara, di dalam keluarga juga bertumbuh nuansa demokrasi yang disebutnya "demokrasi emosi", demokrasi yang didasari cinta kasih, kepercayaan, dialog dan komunikasi. Nilai-nilai inilah yang menjadi landasan etis ketahanan keluarga dewasa ini. Demokrasi ini bersifat orisinal dan menyata dalam relasi interpersonal, suatu hubungan dari muka ke muka, hati ke hati, secara fisik dan emosi. ${ }^{7}$ Degradasi hubungan demokratis keluarga-keluarga kontemporer diduga erat berkaitan dengan sikap tidak bijaksana dalam menjaga etika dasar demokrasi keluarga yang salah satunya diakibatkan oleh sikap lepas kendali teknologi digital yang bukannya menjanjikan ikatan yang lebih akrab, malahan sebaliknya mendistorsi komunikasi dan relasi dalam keluarga.

\section{B. METODE PENELITIAN}

Pertanyaan-pertanyaan utama dalam tulisan ini adalah: bagaimana konsep demokrasi dalam keluarga? Apa saja pilar-pilar etis demokrasi dalam keluarga? Bagaimana contoh penerapannya? Bagaimana pula implikasi teknologi digital terhadap paham demokrasi dalam keluarga? Untuk mendalami pokok persoalan di atas, metode yang digunakan adalah studi pustaka dengan membaca sumber-sumber relevan, mencatat dan mengolah bahan penulisan.

Adapun sumber-sumber primer berasal dari buku-buku dan jurnal-jurnal penelitian yang berkaitan dengan topik-topik demokrasi dalam keluarga dan

${ }^{6}$ Herna Alifiani, Nurhayati, Yulia Ningsih. (2019). “Analisis Penggunaan Gadget Terhadap Pola Komunikasi Keluarga", dalam Faletehan Health Journal, 6 (2), hlm. 52.

7 Anthony Giddens. (2003). Runaway World: Bagaimana Globalisasi Merombak Kehidupan Kita, terj. Andry Kristiawan S dan Yustina Koen S, Jakarta: Gramedia. 
dinamikanya dalam ruang interaksi teknologi digital sekarang in. Berkaitan dengan itu, kajian deskriptif kualitatif ini menggunakan pendekatan hermeneutika dengan mengeksplorasi topik-topik tentang demokrasi keluarga, menginterpretasi konsepkonsep dan fakta-fakta demokrasi keluarga, dan membuat suatu uraian akhir yang komprehensif, sistematis, dan teliti.

\section{ANALISIS DAN PEMBAHASAN}

\section{Keluarga sebagai Locus Demokrasi}

Dari perspektif psikologi perkembangan, internalisasi ide-ide demokrasi kepada seseorang terjadi melalui beberapa tempat: keluarga, sekolah, dan masyarakat. Dari tempat-tempat tersebut, ada semacam konsensus umum bahwa keluarga adalah agen sosialisasi utama. ${ }^{8}$ Alasannya, di dalam keluarga, setiap orang merasakan pengalaman eksistensial, pengalaman bahagia, cinta, kepedulian, dan perhatian. Seorang pribadi bahagia di dalam keluarga, menurut Tolstoy, akan bertumbuh menjadi seorang warga negara yang baik. Sebaliknya, orang yang tidak bahagia di rumah, berada dalam lingkungan keluarga buruk dan tertekan, akan memicu persoalan dan instabilitas sosial bernegara. ${ }^{9}$

Menurut Wardle, di dalam keluarga pertama kali bibit-bibit (seedbed) demokrasi mulai bertumbuh. Tempat seseorang mengenal diri, ruang belajar bersikap baik terhadap sesama, dan kebiasaan untuk melakukan pendekatan dalam mengatasi masalah. Keluarga adalah rumah demokrasi, di mana anak belajar pertama kali tentang kerja sama, komitmen, pentingnya berbagi, pengorbanan, dan kesetiaan. Keluarga seperti sebuah pemerintahan kecil yang mengatur diri sendiri (selfgovernance). Orang tua dianggap sebagai pendidik demokrasi yang mengajarkan anggotanya cara beradaptasi terhadap kekurangan, perasaan peduli terhadap sesama, menjadi bahagia, kebebasan cinta, taat terhadap kewajiban, dan belajar menjadi warga negara yang kritis, serta memiliki keterampilan sosial dalam semangat kerja sama dan saling menghormati. Bangsa dan negara tidak lain daripada ruang ekspresi dan manifestasi potensi demokrasi dari dalam keluarga. Itulah sebabnya, Ringen menegaskan bahwa keluarga "institusi politik" (political institution). ${ }^{10}$

Idealnya, kultivasi dan restorasi kehidupan bernegara demokratis dilakukan secara top-down dan bottom-up sekaligus, maka prosesnya harus sampai pada akarakarnya yakni kehidupan keluarga. Demokrasi tidak hanya menjadi santapan (talking democracy) para elit, akademisi, birokrat, dan politisi seperti tampak dalam politik mainstream selama ini, melainkan harus menyata dalam aktivitas hidup harian (demokracy in the making) hingga ke tengah keluarga. Selama ini, elit-elit negara

${ }^{8}$ Marta Miklikowska, Hellena Hurme. (2011). “Democracy begins at home: Democratic Parenting and Adolescent's Support for Democratic Values", dalam European Journal of Developmental Psychology. hlm. 2 .

${ }^{9}$ Lynn D. Wardle. (2000). “Relationships Between Family And Government”, dalam California Western International Law Journal, Vol. 3, No. 1., hlm. 4

10 Stein Ringen. (2007). What Democracy is For: On Freedom and Moral Goverment, New Jersey: Princeton University Press. 
tampaknya enggan untuk melakukan agenda transformasi sosial hingga ke tingkat akar rumput. Begitulah keluarga-keluarga Indonesia masa kini dibiarkan tidak terurus sehingga di dalam percaturan negara tidak sedikit elit-elit berwajah feodal dengan ambisi kekuasaan dalam wujud kolusi, korupsi, politik balas budi, dan eksklusif. Sebagai fondasi berdirinya negara, keluarga harus diberdaya sesuai dengan corak aslinya yang demokratis. Keluarga tidak hanya menjadi penonton alur cerita yang dikendalikan negara. Indonesia adalah bangsa yang indah, negara yang dibangun di atas semangat kekeluargaan, sedangkan faktanya, negeri ini diubah oleh Orde Baru menjadi "negara keluarga"11 - negara milik keluarga-keluarga tertentu.

Perbaikan dua arah (keluarga dan negara) itu perlu karena, seperti ditegaskan Anne McClintock, kekuasaan dalam keluarga paralel dengan kekuasaan dalam kehidupan berbangsa. Paralelisme itu ditengarai oleh daya-daya maskulinitas. Apa yang kita sebut kebangsaan dicirikan oleh daya-daya maskulin dan keluarga. "Kebangsaan sering digambarkan melalui ikonografi keluarga dan ruang domestik" demikian ungkapan McClintock. Mengutip hasil observasi dari Frantz Fanon, dalam Black Skin, White Mask, McClintock menjelaskan bahwa kita tidak dapat memahami struktur keluarga tanpa teori kekuasaan gender dalam keluarga. ${ }^{12} \mathrm{Hal}$ ini memiliki implikasi bahwa problematika hidup bernegara merefleksikan problematika kehidupan keluarga. Korupsi, skandal jabatan, penipuan, kejahatan sosial dalam realitas bernegara berakar pada simtom-simtom sosial dalam keluarga. Pun sebaliknya, perceraian, perselingkuhan, kekerasan terhadap anak dan perempuan serta berbagai skandal dalam keluarga melahirkan wajah sosial bernegara yang seram. Jadi, korelasi keduanya bersifat simetris. Jika keluarga-keluarga kuat, maka negara pun ikut kuat. Seandainya eksistensi keluarga-keluarga menjadi lemah, negara akan dirundung banyak masalah. Dalam rangka itu, menurut Plato, negara perlu dikonstruksi dalam semangat kekeluargaan. "Di dalam negara, kamu semua bersaudara." Hal ini memperkuat pepatah kuno berbunyi: "build up your family before building up your country" (benahi dahulu keluargamu, baru setelah itu engkau membangun negaramu). ${ }^{13}$

\section{Prinsip-Prinsip Etis Demokrasi dalam Keluarga}

Demokrasi yang hendak dihidupkan dalam keluarga adalah analogisasi dari anutan demokrasi di negara kita. Karena itu, visi, misi, etika, relasi, dan peraturan yang terdapat dalam sistem negara demokratis terdapat dalam keluarga. Pun sebaliknya, konteks demokrasi negara perlu belajar dari praktik demokrasi dalam keluarga. Seperti halnya demokrasi bernegara, dalam demokrasi keluarga, hubungan antar individu didasarkan pada faktor keintiman (chemistry). Dasar dari keintiman adalah cinta kasih. Cinta diiringi rasa percaya dan saling percaya (active trust).

11 Taufik Abdullah. (2009). Indonesia: Toward Democracy, Singapura: Institute of Southeast Asian Studies Publishing.

12 Richard T. Rodriguez (2009). Next of Kin: The Family in Chicano/a Cultural Politics, USA: Duke University Press.

13 Richard A. Nelwan. (2017). Membangun Keluarga Demokratis, Ruteng: Penerbit STKIP Santu Paulus, hlm. xiv. 
Kepercayaan dan keintiman memberi ruang terbuka bagi dialog dan komunikasi. Menurut Giddens, komunikasi dalam demokrasi keluarga tidak akan berjalan tanpa kepercayaan. Dialog dan komunikasi akan efektif jika diikuti rasa hormat dan kesetaraan. Dialog terbuka dan setara merupakan ciri utama demokrasi. Itulah sebabnya Giddens mengutarakan bahwa demokrasi keluarga justru hancur ketika sifat-sifat dari sistem otoritarianisme seperti kekerasan dan kekuasaan masih dipertontonkan pada hubungan setiap anggota keluarga. Prinsip-prinsip demokrasi publik harus sama kuat dengan demokrasi keluarga jika prinsip-prinsip etis demokrasi di atas dihayati dalam kehidupan sehari-hari di dalam interaksi keluarga. ${ }^{14}$

Demokrasi menentang praktik-praktik ikatan primordial. Di dalam keluarga tradisional yang bersifat aristokrat-patriarkis, sang ayah dan kaum laki-laki menganggap diri raja di istana keluarganya, sehingga produk-produk hukum lahir dari imajinasi sepihaknya untuk menguntungkan dirinya sendiri. Sementara, di dalam keluarga modern demokratis, keluarga dibangun di atas etika kesetaraan, keterbukaan, kebebasan, dan persaudaraan. Agar bertumbuhnya etika demokrasi, pasangan keluarga perlu melakukan otokritik terhadap pola, praktik dan komitmen kebersamaan.. Kebersamaan berarti bersama-bersaudara (menunjukkan kekitaan, atau pada satu pihak yang sama), atau bersama-sama berbuat sesuatu (bekerja sama). Kebersamaan mensyaratkan kesadaran 'saling tergantung' dalam rangka optimasi, peluang dan sinergi yang bermanfaat bagi mitra yang bersatu guna mencapai visi-misi bersama melalui organisasi keluarga yang dibentuk. Optimasi, peluang, sinergi hanya bisa dicapai bila kata 'sama' pada kata 'bersama' dikaitkan dengan aspek kemitraan yang 'setara' antarpihak yang akan bersepakat untuk bersatu. Bila kesepakatan ini tidak dibuat, bandul kekuasaan otoritarian dapat berputar kembali dan lonceng maut perpecahan keluarga menunggu kesempatan berdentang. ${ }^{15}$

\section{Tantangan Digitalisasi dalam Keluarga Demokratis}

Dualisme "realitas-virtualitas" de facto berakar dalam sejarah manusia. Pada Abad Pertengahan, ketika era agama dan seni mendominasi, virtualitas dilakukan secara masif untuk mengekspresikan unsur-unsur estetis dalam agama dan seni. Di era industrial selanjutnya terjadi proses reifikasi virtual, namun unsur dualitasnya tetap dipertahankan. Sementara pada abad pos-industri seperti sekarang, masyarakat digital ditandai suatu fenomena virtualisasi secara intesif. Realitas dimodifikasi ke dalam tampilan-tampilan komputer. Lingkungan riil pun mulai kehilangan esensinya lantaran dominan ditampil dalam bentuk dunia tiruan. Tetapi, virtualisasi tidak hanya membuat realitas menjadi samar-samar; ia juga membawa proses kilas balik (tren reifikasi) dari virtualitas kepada realitas. Sebagai contoh, sepuluh tahun lalu, orang memprediksi cuaca dari termometer yang dipasang di luar rumah, sekarang orang membaca data-data internet atau mengaktifkan aplikasi software pada perangkat mobile untuk membaca dan memprediksi realitas cuaca. ${ }^{16}$ Dengan semakin padatnya

${ }^{14}$ Richard A. Nelwan. (2017). Ibid, hlm. 76-77.

${ }^{15}$ Richard A. Nelwan, ibid, hlm 77.

${ }^{16}$ Ilya Levin, "Cultural Trends in a Digital Society", dalam dalam Proceedings of TMCE 2014, May 19-23, 2014, Budapest, Hungary, hlm. 115. 
manusia, kita tidak lagi memerlukan cara-cara pramodern yang lambat. ${ }^{17}$ Kita membutuhkan presisis, efektivitas dan efisiensi. Jawabannya adalah teknologi.

Virtualisasi menggejala pada segala dimensi, salah satunya pada dimensi sosial demokrasi. Jika kita melihat realitas pada level negara, demokrasi telah mengalami modifikasi dari bentuk-bentuk lama ala Athena kepada model baru berbasis digital. Intervensi teknologi di dalam proses berdemokrasi memungkinkan adanya demokrasi digital untuk meningkatkan partisipasi publik dalam mengontrol kebijakan umum. Sebab, konsep kewarganegaraan Athena, tempat pertama kali demokrasi berasal, menuntut keterlibatan aktif setiap warga. Di dalam politik demokrasi, teknologi diharapkan dapat meningkatkan kemampuan publik untuk membangun opini yang dapat mempengaruhi kebijakan. ${ }^{18}$

Sayangnya, negara berkembang seperti Indonesia menghadapi problem kesenjangan digital (digital devide) yang memungkinkan nilai-nilai demokrasi di tingkat negara - dan bahkan dalam keluarga - sulit dirasakan di era digital ini. Anak-anak dan remaja, misalnya, yang merupakan kelompok rentan dalam proses identifikasi diri terhadap sosialisasi demokrasi kurang mampu memanfaatkan internet untuk aktivitasaktivitas produktif. Reginasari dalam risetnya mengafirmasi bahwa remaja kita lebih suka terlibat dalam chat war (82 persen) dan obrolan-obrolan yang tidak produktif. ${ }^{19}$ Demikian pula akses terhadap informasi publik untuk membentuk sikap dan mental demokratis yang dibangun di atas rasionalitas kritis tampak sulit dicapai.

Dalam konteks penerapan nilai-nilai demokrasi keluarga pada era menjamurnya media sosial online sekarang ini, kecenderungan komunikasi menjadi begitu jauh dari dialog interpersonal. Sulit dibayangkan dua orang adik-kakak dan bahkan suami-isteri yang bertemu setelah pulang ke rumah, saling menyapa sebentar, seterusnya sibuk dengan ponsel android masing-masing di tangan. Bisnis digital mengeksploitasi persaudaraan dengan menjadikan anak-anak utamanya sebagai target pasar. Hubungan sosial dan kebiasaan tatap muka pada keluarga yang masih dirasakan sepuluh tahun lalu, mulai memudar akibat hubungan impersonal manusia pada teknologi dan ekonomi. Manusia tunduk pada mesin teknis di tangan. Hubungan manusia dengan materi, menurut Louis Dumount, jauh lebih erat daripada hubungan manusia dengan sesamanya. Tujuannya tidak lain daripada proses produksi mental manusia agar berorientasi pada gejala componentiality, di mana setiap orang akan mirip komponen mesin, manusia robot, mekanistik, fungsional, dan gampang diatur sesuai sistem teknologi dan ekonomi yang berkembang.

Katherine Hayles mengatakan bahwa efek kemajuan zaman digital ini sering kali berakibat pada dua tren, yakni alienasi (alienazion) dan alienisasi (alienization). Teknologi yang diciptakan untuk membantu pekerjaan justru memperbudak

${ }^{17}$ David Ray Griffin. (2005), Visi-Misi Posmodern, Yogyakarta: Kanisius, hlm. 183.

18 Siska Sasmita. (2011). “Demokrasi dalam Bingkai Digital”, dalam jurnal Demokrasi, Vol. 10, No. 2., hlm. 160

19 Annisa Reginasari, "Mediasi Orang Tua dalam Literasi Digital dan Internet”, dalam Tina Afiatin, dkk. Psikologi Perkawinan dan Keluarga: Penguatan Keluarga di Era Digital Berbasis Kearifan Lokal, Yogyakarta: Kanisius, 2018, hlm. 91-92. 
penciptanya sendiri. Lebih tragis lagi, kesadaran dan perilaku manusia mengalami teknologisasi: bertubuh manusia tetapi bermental, bersikap dan bertingkah teknologis. Manusia berubah menjadi lain dari dirinya, menjadi seperti alien, yang tidak begitu mengenal diri, fisik dan pikirannya yang unik, lebih suka mengikuti sistem kerja robotik..$^{20}$ Sungguh sebuah ironi besar bahwa revolusi teknologi di bidang komunikasi digital bukan justru membuka ruang makin luas dan intensnya komunikasi demokratis berlandaskan kepercayaan, kesetaraan dan keterbukaan, malahan sebaliknya orang akan menjadi sangat kesepian di tengah hingar bingar padatnya manusia. Bonus demografis di mana angkatan usia produktif di negara kita bukannya disambut dengan semangat berbagi, justru muncul beragam problem yang bersifat eksponensial. Demikian halnya dalam keluarga modern. Begitu mudah dan murahnya mendapatkan perangkat teknologi semacam ponsel android, orang tua sering tanpa berpikir panjang menyediakan fasilitas ini untuk menenangkan anak-anak sehingga terbebas dari keharusan membangun komunikasi "hati ke hati" antara orang tua dan anak bahkan juga antara suami dan isteri. Semuanya diambil alih oleh teknologi. Sampai pada taraf tertentu, komunikasi menjadi dangkal, saling mengenal dan meneguhkan menjadi terabaikan. Alhasil, potensi keretakan keluarga justru masif dalam era media on-line kini. Riset di Amerika Serikat (2011) mendeskripsikan (2011) sisi distorsi komunikasi dalam keluarga. Quality time orang tua dan anak sangat berkurang. Di Indonesia, riset yang dilakukan Alfiani, Nurhayati, dan Ningsih menunjukkan bahwa 97,8\% responden yang aktif gadget kurang memiliki komunikasi baik dalam keluarga. Demikian juga dalam riset yang dilakukan Nurchayati (2016), $78 \%$ responden mengaku kurang komunikatif dengan keluarga atau orang tua. ${ }^{21}$

Di sini sentuhan kasih sayang melalui kontak fisik semisal tepukan pundak, belaian kasih, dan kecupan orang tua terhadap anak menjadi jarang dan hanya bisa dipantau melalui aplikasi perangkat ponsel. Ini tentu saja praktis bagi orang tua, tetapi juga membawa petaka bagi masa depan anak yang karena keasyikannya dengan dunia maya dan permainan-permainan online, cenderung lupa diri dan abai dengan realitas nyata kehidupan dunia sosial kemasyarakatan dan kebangsaan.

Pada sisi lain, ada panorama yang berbeda dalam kehidupan ekonomi keluarga. Teknologi digital tidak bebas nilai tetapi telah menjadi instrumen sistem ekonomi dalam berekspansi untuk kepentingan akumulasi modal. Handphone dan internet dibanjiri iklan-iklan yang mendorong konsumerisme, hedonisme, dan materialisme. Ideologi-ideologi itu senjata rahasia perekonomian yang membius pikiran orang-orang, terutama bagi yang sudah berkeluarga, untuk lebih banyak berbelanja dan mengumpulkan harta (konsumtif) daripada menghasilkan (produktif) lantaran sistem produksi telah dikendalikan. Seperti dilansir Jean Baudrillad, di era masyarakat teknologi dan konsumtif ini, orang-orang sering menderita sakit, yakni "sakit kelelahan" kronis yang tampak kasat mata di mana-mana. Orang-orang

20 Yohanes Mariano Dangku, “Relevansi Makna Guru dalam Skrip Budaya Manggarai bagi Guru pada Era Pascahuman”, dalam Yohanes S. Lon (ed.), (2019), Membangun Manusia Seutuhnya: Perspektif Agama, Kebudayaan dan Pendidikan, Ruteng: Penerbit Unika Santu Paulus Ruteng, hlm.158.

${ }^{21}$ Herna Alifiani, Nurhayati, Yulia Ningsih, (2019), “Analisis Penggunaan Gadget Terhadap Pola Komunikasi Keluarga”, dalam Faletehan Health Journal, 6 (2), hlm 54. 
mengalami kelelahan yang teramat sangat. Kelelahan yang dimaksud adalah "kelelahan saraf", kelelahan psikosomatik, yang mengarah pada depresivitas. ${ }^{22}$ Sekian banyak pakaian dan ornamen yang tidak terpakai di dalam rumah, tekanan di tempat kerja, dan obsesi untuk hidup enak dan ingin jalan-jalan, gaya-gayaan sebagai efek hidup hedonistik yang tampak dalam budaya fashion, semua itu mendatangkan kelelahan. Kelelahan, bagi Baudrillad, adalah persoalan global seperti halnya kemiskinan. Sekiranya keluarga-keluarga masa kini jeli dan bijak dalam mengatur keuangan keluarga untuk membentuk komunitas keluarga yang sehat, membentuk negara yang demokratis.

\section{Solusi}

Pertama, manajemen keluarga. Manajemen demokrasi dalam keluarga tampak salah satunya dalam rapat rutin keluarga. Rapat adalah implementasi konsep manajemen yang paling sederhana. Ia ibarat rapat umum pemegang saham perusahaan, sekolah, kantor bisnis, atau sidang paripurna dewan perwakilan rakyat. Pada rapat keluarga, setiap orang memiliki kedudukan yang setara. Di sana dibicarakan berbagai persoalan dan aktivitas, termasuk janji, kesepakatan, dan aturan, berikut perubahan-perubahannya. Dalam rapat keluarga juga dibicarakan tentang rencana kegiatan dan keuangan serta evaluasi dan kritik terhadap realisasi pelaksanaannya. Karena itu, rapat keluarga sebaiknya diadakan secara periodik minimal dua kali sebulan. Tujuannya untuk pembentukan suasana demokratis sekaligus media pendidikan demokratis bagi anak-anak. Karena itu, mereka perlu dibiasakan untuk hadir dalam rapat, bahkan sejak balita sekalipun. Dialog bersifat kesetaraan. Tidak ada dominasi. Tidak ada pengkultusan individu lantaran senioriotas dan kontribusi penghasilan. Relasi dialogal berlaku etika "dipimpin oleh hikmat kebijaksanaan dalam permusyawaratan".

Rapat anggota keluarga adalah bagian dari proses komunikasi politik demokrasi dalam keluarga. Di situ anak-anak akan belajar berdiskusi, berdebat, beradu argumen, bernegosiasi, mengambil keputusan dan membuat kesepakatan, kemudian bekerja sama sesuai kesepakatan itu. Keluarga ibarat "akademi politis". Setiap anggota belajar menghayati hak dan kewajiban, kebebasan dan tanggung jawab, untuk menjadi warga negara yang demokratis. Prinsip kerja sama dalam "akademi politis" ini adalah: bersatu kita teguh bercerai kita runtuh, berat sama dipikul ringan sama dijinjing, berdiri sama tinggi duduk sama rendah, setara di hadapan dan menepati janji kesepakatan, menghargai kebebasan dan keterbukaan, berkomunikasi dari hati ke hati dalam suasana persaudaraan.

Kedua, keluarga demokratis juga terlihat dari tata kelola keuangan keluarga. Pada era globalisasi ekonomi ini, orientasi keluarga pada aktivitas ekonomi lebih menonjol dari sebelumnya. Sebagai organisasi konsumen (cost centered organization), manajemen keuangan organisasi modern yang baik perlu membudaya dalam tata kelola keuangan keluarga modern. Ada keluarga yang menyadari perlunya budget,

\footnotetext{
22 Silvester Ule. (2011). Terorisme Global: Tinjauan, Kritik, dan Relevansi Pandangan Jean Baudrillard. Ledalero: Penerbit Ledalero.
} 
pencatatan kas, biaya, penghasilan, hutang, piutang, dan tabungan, tetapi lebih banyak yang tidak mencatatnya atau mencatat hanya sepintas lalu. Mungkin karena manajemen keuangan keluarga terlalu sederhana bila dibandingkan dengan manajemen keuangan usaha. Padahal, kesederhanaan justru merupakan peluang kemudahan bagi keluarga untuk mendidik anak-anak, bukan dari segi pengetahuan teknis administratifnya saja, melainkan terutama muatan etika demokratis dan norma manajemen keuangan. Jika hal ini dibiarkan maka bukan tidak mungkin dari dalam keluarga akan terbentuk warga negara yang rawan skandal dan tipu-menipu di masyarakat dan negara. Ada juga anggota keluarga yang sukses di tempat kerja dan paham pembukuan, tetapi kinerja tersebut tidak dihayati dalam keluarga. Banyak keluarga tidak menerapkan prinsip-prinsip manajemen keuangan membuktikan bahwa sickers down effect pengetahuan, pengalaman, dan profesi orangtua di tempat kerja tidak selalu compatible dengan suksesnya tata keuangan keluarga. Mereka tidak menyadari konsep neraca tunggal keuangan keluarga. Seperti halnya negara yang memiliki neraca utama yakni ABPN, keluarga seharusnya memiliki neraca tunggal. Sering kali dalam kenyataan, bila kedua orang tua bekerja, umumnya baik sang suami maupun sang istri masing-masing memiliki neraca keuangan pribadi, seperti di dompet atau rekening bank atas nama pribadinya. ${ }^{23}$

Tantangan kehidupan keluarga di era digital ini adalah kehadiran aplikasiaplikasi yang memungkinkan adanya transaksi-transaksi gelap yang tidak diketahui pasangan di rumah. Arus privasi akut terpola dalam perilaku yang ingin menang sendiri, ingin mengatur diri tanpa didikte pasangan. Pemasukan dan pengeluaran tak harus diketahui siapa saja bahkan oleh pasangan sekalipun. Apalagi jika seseorang sudah menduduki posisi penting dalam kariernya, mindset-nya dapat saja berubah. Gaya hidupnya mulai berbeda. Ia menganggap diri hebat dan paling berjasa, dan ketika kembali ke rumah ia ingin diperlakukan istimewa. Ia lupa kalau penghasilan adalah milik organisasi asalnya, yaitu keluarganya. Hubungan asimetrikal profesi dan keluarga di mana keluarga dinomorduakan berpotensi timbulnya diskomunikasi, frustrasi, perang dingin, dan bahkan perceraian. Connidis dan McMullin mengungkapkan bahwa stres dan ketidakharmonisan disebabkan antara lain oleh kesenjangan penghasilan di dalam keluarga. ${ }^{24}$

Selain itu, apa yang dapat kita amati dalam kehidupan profesi masyarakat dan negara seperti penggunaan neraca ganda perusahaan (neraca untuk pajak yang berbeda dengan neraca untuk mengajukan kredit ke bank), korupsi, politik uang, kantor-kantor departemen di pemerintahan yang memiliki dana-dana taktis di rekening pribadi pimpinan, atau rekayasa-rekayasa laporan keuangan (window dressing), terjadi karena di keluarga-keluarga kita tidak dibiasakan menggunakan joint escrow account, rekening bersama, dan orangtua tidak terbiasa terbuka terhadap satu dengan lainnya atau terhadap anak-anak tentang keuangan keluarga. Hanya segelintir keluarga yang menyadari janji persatuan suami-istri ketika menikah tercermin dalam

${ }^{23}$ Richard A. Nelwan. (2017). Membangun Keluarga Demokratis, Ruteng: Penerbit STKIP Santu Paulus, hlm. 106-107.

${ }^{24}$ Afiatin, Tina, dkk. (2018). Psikologi Perkawinan dan Keluarga: Penguatan Keluarga di Era Digital Berbasis Kearifan Lokal. Yogyakarta: Kanisius., hlm. 148. 
bentuk ranjang yang satu, atau neraca tunggal keluarga. Justru inilah seharusnya keluarga memiliki neraca atau joint escrow account (rekening bersama para anggota keluarga) yang mencerminkan demokrasi. Posisi family joint escrow account ini tertinggi di dalam keluarga. Hal ini bertujuan untuk mendidik etika kesetaraan dan teknik manajemen keuangan yang terbuka, tertib dan sehat. ${ }^{25}$ Kehadiran teknologi yang kian canggih menurut orang tua untuk mengatur kembali sistem keuangan bagi komunitas keluarga, khususnya anak-anak, agar budget keuangan tidak mengalami defisit dan terlebih lagi terbentuk literasi keuangan yang demokratis dalam diri anggota keluarga. ${ }^{26}$

Ketiga, orang tua sebagai teladan penggunaan gadget. Bagi anggota dan terutama anak-anak yang sudah sampai pada tahap kecanduan gadget, sistem pendidikan yang cocok dilaksanakan di era digital ini adalah model Parenting Immun Selfer atau juga sistem pengontrolan. Dalam hal ini, orang tua mendampingi anak-anak dan mengontrol ketika mereka mengakses konten-konten di media digital. ${ }^{27}$

\section{KESIMPULAN}

Gambaran kehidupan keluarga di era digital ini mengisahkan ambiguitas demokrasi dalam keluarga. Pengalaman ketidakadilan, kesepian yang mendalam, depresi, dan terabaikan akibat kurangnya interaksi dan komunikasi menjadi bumerang bagi keluarga dalam menata hubungan yang demokratis. Hubungan yang demokratis merupakan dasar bagi pembentukan pribadi yang bahagia dan pribadi yang bahagia adalah seorang warga negara yang demokratis. Banyak anggota keluarga justru menyibukkan diri dengan android namun serentak merusak esensi komunikasi, kebebasan dan kesetaraan. Tidak hanya itu, kehidupan di era digital juga rentan terhadap perilaku konsumtif, hedonistik dan individualistik. Banyak orang tua makin sulit, karena memang inilah zaman lepas kontrol (runaway world), di mana implikasi teknologi memperkuat lemahnya otoritas orang tua di hadapan anak. Hilangnya figur ibu atau ayah dalam proses pembentukan karakter demokratis anak pada keluarga merupakan awal masalah rendahnya kualitas negarawan demokratis.

Kehadiran media digital yang sangat masif saat ini tidak hanya telah membawa suatu realitas baru, distorsi komunikasi, retaknya hubungan yang seharusnya ada dalam setiap interaksi keluarga. Hubungan via teknologi adalah hubungan yang diperantarai, dinstrumentasi, dan hal itu menghalangi pandangan mata ketika seseorang berbicara dengan orang lain sambil asyik khusuk memegang android di tangan. Kita sedang berada di bentangan era digital yang sangat dinamis serentak membawa petaka yang kian kompleks dalam hidup berkeluarga. Penderitaan yang tidak dapat dilukiskan adalah penderitaan yang terjadi di dalam keluarga, salah

${ }^{25}$ Richard A. Nelwan. (2017). Ibid, hlm. 106-107.

26 Muyassarah, Pengaruh Perkembangan Teknologi Terhadap Cara Mendidik Anak Dan Dampaknya Terhadap Budget Keuangan Keluarga Muslim," dalam BERDAYA: Jurnal Pendidikan dan Pengabdian Kepada Masyarakat, Vol 1, No.1, 2019, hlm. 7.

${ }^{27}$ Aslan, "Peran Pola Asuh Orangtua di Era Digital”, dalam Jurnal Studia Insania, Mei 2019, hlm. 
satunya karena minimnya komunikasi. Ada bersama harus didefinisi sebagai saling berbagi, saling berkomunikasi, suatu hubungan langsung tanpa perantara, tanpa harus dimediasi oleh sesuatu yang asing bernama teknologi.

\section{REFERENSI:}

Afiatin, Tina, dkk. (2018). Psikologi Perkawinan dan Keluarga: Penguatan Keluarga di Era Digital Berbasis Kearifan Lokal. Yogyakarta: Kanisius.

Alifiani Herna, Nurhayati, Ningsih Yulia. (2019). “Analisis Penggunaan Gadget Terhadap Pola Komunikasi Keluarga", dalam Faletehan Health Journal, 6 (2) (2019) 50-55 www. journal.lppm-stikesfa.ac.id/ojs/index.php/FHJ.

Giddens, Anthony. (2003). Runaway World: Bagaimana Globalisasi Merombak Kehidupan Kita, terj. Andry Kristiawan S dan Yustina Koen S, Jakarta: Gramedia.

Lestari Inda, Riana Agus Wahyudi, Taftarzani Budi M. "Pengaruh Gadget Pada Interaksi Sosial Dalam Keluarga", dalam Prosiding KS: Riset \& Pkm, Volume: 2 Nomor.

Levin, Ilya, "Cultural Trends in a Ditial Society", dalam Proceedings of TMCE 2014, May 19-23, 2014, Budapest, Hungary.

Miklikowska, Marta, Hurme, Hellena. (2011). “Democracy begins at home: Democratic Parenting and Adolescent's Support for Democratic Values", dalam European Journal of Developmental Psychology.

Nelwan, A. Richard. (2017). Membangun Keluarga Demokratis, Ruteng: Penerbit STKIP Santu Paulus.

Prasetyo, Yanu Endar. (2016). "Kesenjangan Digital dan Penguataan E-Demokrasi", dalamlipi.go.id/lipimedia/kesenjangan-digital-dan-penguatan-e-demokrasi/16733

Ringen, Stein. (2007). What Democracy is For: On Freedom and Moral Goverment, New Jersey: Princeton University Press.

Rodriguez, Richard T. (2009). Next of Kin: The Family in Chicano/a Cultural Politics, USA: Duke University Press.

Sasmita, Siska. (2011). "Demokrasi dalam Bingkai Digital", dalam jurnal Demokrasi, Vol. 10, No. 2.

Tapung, Marianus Mantovanny, Edu, Leonangung Ambros, Jaya, Petrus Redy Partus. (2019). “Kemampuan Bermedia dan Daya Kritis Para Mahasiswa *Di Kabupaten Manggarai - Flores", dalam SALAM; Jurnal Sosial \& Budaya Syar-i FSH UIN Syarif Hidayatullah Jakarta Vol. 6 No. 2.

Ule, Silvester. (2011). Terorisme Global: Tinjauan, Kritik, dan Relevansi Pandangan Jean Baudrillard. Ledalero: Penerbit Ledalero.

Wardle, Lynn D. (2000). "Relationships Between Family And Government", dalam California Western International Law Journal, Vol. 3, No. 1. 